\title{
Kyrle Disease and Acquired Perforating Collagenosis Secondary to Chronic Renal Failure and Diabetes Mellitus
}

\author{
Stephan Schreml ${ }^{\mathrm{a}} \quad$ Christian Hafner $^{\mathrm{a}}$ Fabian Eder $^{\mathrm{b}}$ \\ Michael Landthaler ${ }^{\mathrm{a}}$ Walter Burgdorf ${ }^{c}$ Philipp Babilas ${ }^{\mathrm{a}}$ \\ aDepartment of Dermatology and ${ }^{b}$ Institute of Pathology, University Hospital \\ Regensburg, Regensburg, and 'Department of Dermatology, Ludwig Maximilian \\ University Munich, Munich, Germany
}

\section{Key Words}

Hyperkeratosis follicularis et parafollicularis in cutem penetrans - Kyrle disease - Reactive perforating collagenosis . Perforating dermatoses - Transepidermal elimination

\begin{abstract}
A 59-year-old man with chronic renal failure and diabetes mellitus presented with pruritic crusted lesions which histologically were perforating disorders, showing features of both Kyrle disease and acquired perforating collagenosis. The mechanisms of transepidermal elimination and the classification of perforating disorders are briefly discussed. Additionally, we question the concept of perforation, as epidermal damage and exposure of subepidermal substances may artificially present as perforation.
\end{abstract}

\section{Introduction}

Kyrle disease (KD; or hyperkeratosis follicularis et parafollicularis in cutem penetrans) is a perforating dermatosis, first described in 1916 [1]. Apart from KD [2], the perforating dermatoses include elastosis perforans serpiginosa (EPS), perforating folliculitis (PF), and acquired perforating collagenosis (APC; or reactive perforating collagenosis, early/lateonset type) secondary to chronic renal failure and/or diabetes mellitus [3]. The common pathophysiological principle in these disorders is supposedly transepidermal elimination (TEE) of dermal substances, predominantly collagen in APC, keratin in KD and PF, or thickened elastic fibers in EPS. However, features may vary and the composition of the TEE material may contain collagen, elastin, and keratin in one patient. 


\section{Case Report}

A 59-year-old man was diagnosed with perforating dermatosis with lesions resembling both $\mathrm{KD}$ and late-onset type APC. The patient had first noticed skin lesions two years before presentation and he reported no pruritus. Additionally, the patient had diabetes mellitus type 2 and chronic renal insufficiency. He had no history of hemodialysis. Therapy with topical steroids had remained ineffective. On examination, there were multiple follicular and some non-follicular hyperkeratotic papules, predominantly on the shins and the calves. Some of the larger papules exhibited a central depression with an adherent keratotic plug (fig. 1a, b). Additionally, erythematous plaques with central necrosis were found. A punch biopsy showed epidermal acanthosis and papillomatosis, a central ulceration with an overlying serum crust, deposits of degraded collagen and some elastic fibers in the upper dermis, and some lymphocytic infiltration (fig. 1c-f). The microscopy images combined with diabetes mellitus with chronic renal insufficiency pointed to the diagnosis of APC, but the mainly follicular, smaller keratotic papules seemed to fit better with a diagnosis of KD.

The larger keratotic plugs were removed and topical steroid therapy was intensified. The smaller keratotic plugs were regularly debrided and antidiabetic therapy was optimized.

\section{Discussion}

It is hard to discriminate between the perforating disorders. Patterson [3] proposed the following classification system: (i) perforation as an incidental histological finding; (ii) secondary perforation (e.g. in granuloma annulare, pseudoxanthoma elasticum, and chondrodermatitis nodularis chronica helicis), and (iii) primary perforating dermatoses. The latter group includes KD, late-onset APC, and PF in subgroup IIIC, which is also termed acquired perforating diseases other than EPS and early-onset APC. Due to the fact that perforating dermatoses are quite rare [3], little is known about their pathogenesis. However, new findings point to the fact that the interaction of keratinocytes with altered structural proteins plays a decisive role, e.g. $67-\mathrm{kDa}$ elastin receptor overexpression in EPS [4]. In APC, TGF- $\beta_{3}$, MMP-1 and TIMP-1 are overexpressed in lesional skin, indicating changes in extracellular matrix composition [5].

The case of KD and late-onset APC in our patient supports the idea of a common pathomechanism in primary perforating dermatoses (group IIIC according to Patterson) [3]. KD and late-onset APC may be considered morphological variants of the same underlying disease process. However, the question remains whether perforation really exists: in most cases, pruritus leads to scratching, epidermal damage, and alteration of dermal substances (e.g. collagen or elastin). The exposure of altered subepidermal substances through epidermal gaps (e.g. by scratching) may appear as epidermal perforation, i.e. TEE. Continuous imaging of this process remains impossible at the moment; therefore, the TEE concept can neither be proven nor negated.

\section{Disclosure Statement}

The authors have no conflicts of interest to declare. 

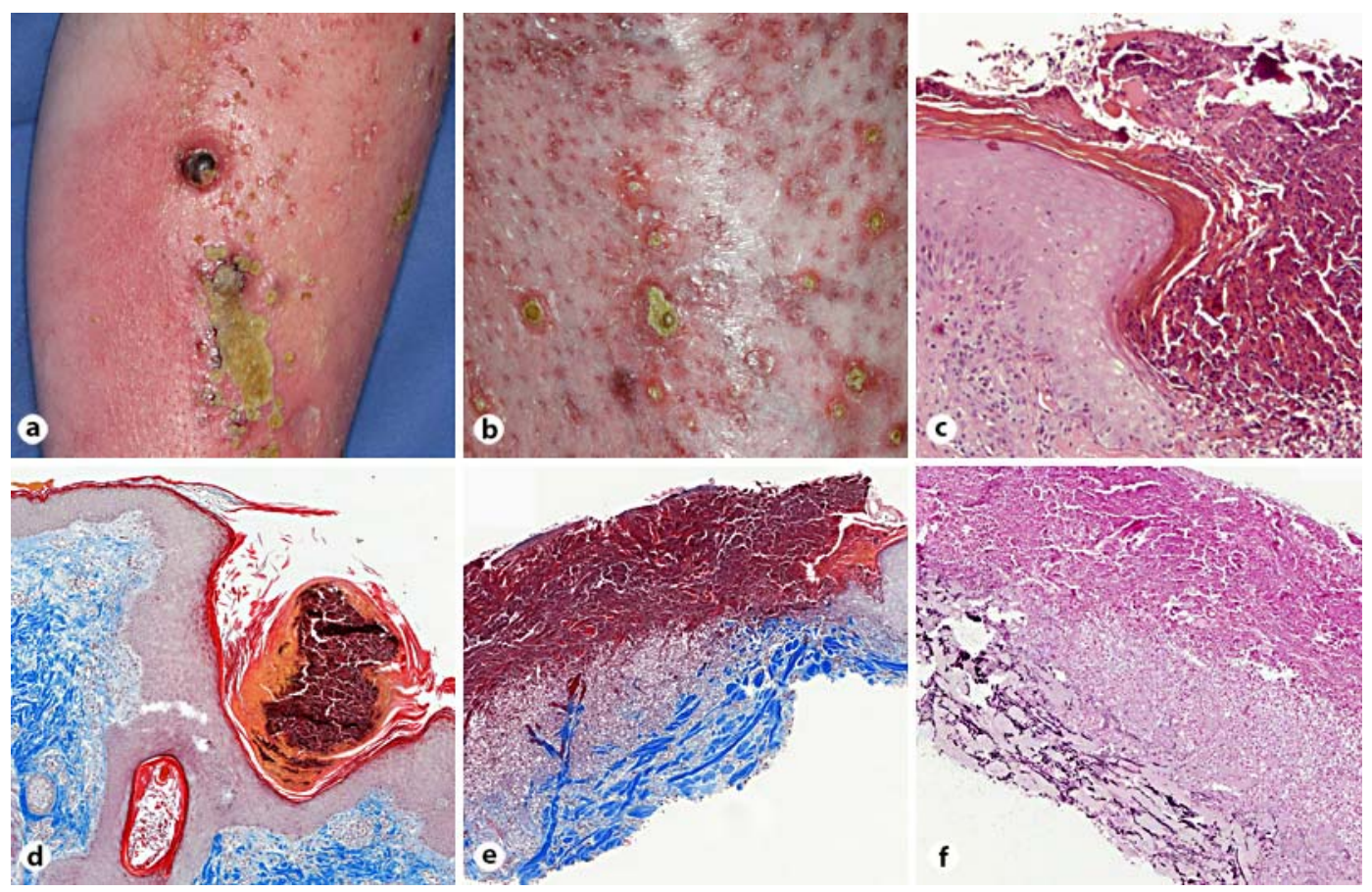

Fig. 1. Clinical presentation and histology. a, b Multiple follicular and some non-follicular hyperkeratotic papules, predominantly on the shins, but also on the calves. Some of the larger papules exhibited a central depression with an adherent keratotic plug. Some erythematous plaques with central necrosis were found. c Epidermal acanthosis and papillomatosis, a central ulceration with overlying serum crust, condensed collagen fibers in the papillary dermis, and sparse lymphocytic infiltration. H\&E stain, $\times 20$. d Widened, almost cystic acro-infundibulum filled with keratin and cell detritus. Masson's trichrome with aniline blue, $\times 50$. e Shallow ulceration with overlying fibrin and dense neutrophilic infiltrate. Degraded collagen fibers are seen in the adjacent dermis. Masson's trichrome with aniline blue, $\times 50$. $\mathbf{f}$ Elastic fibers (dark) and degraded collagen fibers underneath the ulceration. EVG stain for elastic tissue fibers (Verhoeff Van Gieson, Miller), $\times 60$.

\section{References}

1 Kyrle J: Hyperkeratosis follicularis et parafollicularis in cutem penetrans. Arch Dermatol Syph 1916;123:466493.

2 Powell EW: Hyperkeratosis follicularis et parafollicularis in cutem penetrans (Kyrle's disease). Br J Dermatol 1970;83:420-422.

3 Patterson JW: The perforating disorders. J Am Acad Dermatol 1984;10:561-581.

-4 Fujimoto N, Akagi A, Tajima S, Ishibashi A, Nomura K, Matsushita A, Nagai Y, Shishiba K: Expression of the 67-kDa elastin receptor in perforating skin disorders. Br J Dermatol 2002;146:74-79.

-5 Gambichler T, Birkner L, Stucker M, Othlinghaus N, Altmeyer P, Kreuter A: Up-regulation of transforming growth factor-beta3 and extracellular matrix proteins in acquired reactive perforating collagenosis. J Am Acad Dermatol 2009;60:463-469. 